CARPATHIAN JOURNAL OF FOOD SCIENCE AND TECHNOLOGY

journal homepage: http://chimie-biologie.ubm.ro/carpathian_journal/index.html

\title{
DIFFERENCES OF THE PHYSICOCHEMICAL INDICATORS OF \\ BEVERAGES WILD ELDERFLOWER (SAMBUCUS NIGRA) FROM TELEAJEN VALLEY, ROMANIA, ACCORDING TO THE USED TECHNOLOGY
}

\begin{abstract}
Maria Lidia Iancu ${ }^{1}$
I"Lucian Blaga" University of Sibiu, Faculty of Agricultural Sciences, Food Industry and Environmental Protection, 5-7, Ion Raţiu Street, Sibiu, 550012, Romania

$\triangle_{\text {maria.iancu@ulbsibiu.ro }}$

https://doi.org/10.34302/crpjfst/2020.12.3.16

Article history: ABSTRACT

Received:

28 March 2020

Accepted:

25 August 2020

Keywords: Romania,

Juice elderflower,

Wilde elder,

Physico-chemical indicators,

Compote technology.

ABSTRACT
Elderflowers beverages have a hydrating effect and a chemical composition that influences the sensory characteristics and the values of the main quality indicators. This paper focused on evaluating the modifications of 15 physicochemical quality indicators for 4 samples, elderflower beverages, which differ from one another by the applied technology, the parameters of operations and processes and the recipe. Fresh elderflowers, water, sugar and lemon were used for preparing the samples which is the classic technology of making "socata" and an original combination of obtaining a new product, namely "the elderflower compote". The analysis methods used were quantitative methods for determining the reducing sugar, the volatile components which give the volatile acidity, the fixed acidity, the physical methods based on different principles and modern equipment. Changes in all the quality indicators were reported as follows: the production yield of the liquid fraction $90-98 \mathrm{w} / \mathrm{w} \%$, density $1.0343-1.0590 \mathrm{~g} / \mathrm{cm}^{3}$, the kinematic viscosity $1.30087-1.8390 \mathrm{~m}^{2} \mathrm{~s}^{-1}$, content values of the total soluble solids (TSS) 9.5-15.4 ${ }^{\circ}$ Brix, with a correlation coefficient below $50 \%$, depending on the used method. Total sugar/acid ratio is 47.74-140.85 and total sugar $10.2-14.96 \%$. The new product, the compote, has values of the indicators that fall within the range of the elderflower beverages. Thus, it is characterized by the highest value of the production yield $98 \mathrm{w} / \mathrm{w} \%$, of the TS/TA ratio (140.85), of the density $1.0590 \mathrm{~g} / \mathrm{cm}^{3}$, of the kinematic viscosity $1.83902 \mathrm{~m}^{2} \mathrm{~s}^{-1}$, of the TSS $=15.4{ }^{\circ}$ Brix, of the TS $14.96 \%$ and the lowest of the SDR- $4.5 \%$ (direct reducing sugars).
\end{abstract}

\section{Introduction}

The wild elder shrubs (Sambucus nigra) are distinguished by their white and fragrant inflorescences occurring in May-June. The elderflowers are therefore a raw material available to both food and pharmaceutical manufacturers. Tea, syrup, tonic, ice cream, yoghurt and other beverages can be prepared as food (Vlachojannis et al., 2015; Mikulic Petkovsek et al., 2016; Olejnik et al., 2016).
There is a beverage made of elderflowers which is called "cordial". It seems to originate in the Roman era, with powerful versions of the Victorian era, and now it is predominant in Central Europe, especially in England, Germany, Austria, Romania, Hungary and Slovakia. It is a syrup, flavored with fresh elderflowers and lemon as a source of citric acid. It is served diluted with tap water or carbonated water. 
Spring flowers from the end of May until the beginning of June or later are used to this purpose. The hermaphrodite flowers have a diameter of $10-25 \mathrm{~cm}$, the individual ones are white with five petals, 5-6 $\mathrm{mm}$ in diameter and are pollinated by insects. They are fragrant and somewhat succulent flowers with a particular aroma and flavor (Morton, 2004; Day, 2010).

This juice, elderflower cordial, can be made relatively easily at home, but it is also a marketed product. There are currently soft drinks that use a combination of flavors that imitate the natural one. This drink, thus obtained, is cheaper and thus money and labor are saved (Morton, 2004). Elderflower beverages are prepared and consumed (Morton, 2004) as a refreshing and stimulating product designed for a medical purpose for various diseases (cardiac, diabetes).

There are technological studies on natural juices obtained from different raw materials such as fruits and vegetables, matured and consumed fresh or preserved. The reason why juices are recommended is that for medical reasons certain people cannot consume the vegetables as such (Mihalev et al, 2018). In general, fruits are used for juices, and in human nourishment, flowers are used as spices. In the practice of their processing, flowers are used to make comfiture (roses, for example, or lilac) for their special sensory but also therapeutic characteristics (Walkowiak-Tomczak et al., 2017).

Wild elderflowers Sambucus nigra belonging to the Adoxaceae family, Sambucus genus, are a morphological part of the shrub. They are extremely popular among consumers in Romania and throughout the world. In Romania, they are usually used fresh, and the manufactured beverages are based on other raw materials: water, sugar, lemon and high fermentation yeast belonging to the species Saccharomyces cerevisiae. According to FOASTAT, the production of wild elderflowers used in the beverage production is not specified (FOASTAT, 2017) but is a sustainable and, more importantly a free resource. These morphological parts are seasonal in nature as well as the juice production. In the way in which the technology is applied for the "socata", the nutrient principles and the volatile components are little affected by the operational parameters and the quality indicators have values that need to be determined.

The main objective of this study is to investigate by means of a comparative analysis the values of the quality indicators for a new product made of elderflowers, namely the fresh elderflower compote. As secondary objectives the following will be investigated: the production yield, the comparative analysis of the values of the physicochemical quality indicators (total acidity, volatility, relative density, $\mathrm{pH}$, viscosity, reducing sugar, soluble dry matter, real dry matter, total sugar/total acidity ratio), the determination of the correlation coefficient for the soluble dry substance content values determined using apparatus operating according to different principles and the correlation between these values.

\section{Materials and methods \\ 2.1. Materials}

\subsubsection{Raw materials and technologies}

The technology and the recipe were discussed in a prior study (Iancu, 2018). The studied samples are similar but have been coded differently because the analyses intended for this study differ from the sensory ones. The coding of the samples is different and is based on the differences in the applied technology. Thus, there were prepared: elderflower juice fermented with yeast $(\mathrm{EjF})$; elderflower juice fermented with yeast preserved by pasteurization (EjFP), elderflower juice unfermented with yeast preserved by pasteurization (EjnFP), elderflowers compote with sugar (EC). 


\subsubsection{Determination of production yield}

The Yield of juice For $100 \mathrm{~g}$ of the liquid fraction was calculated based on the formula:

$$
I Y=\frac{w_{j}}{w_{r w}}-100,[\%]
$$

In which: JY - the yield in juice, $\mathrm{w}_{\mathrm{rw}}$ - the amount of raw material [g] (solid part and liquid part), wj- the amount of juice obtained from this raw material (Kaack, 1997).

\subsubsection{Physico-chemical characteriyzation of juice and compote}

Appropriate choice of analysis package was done in order to highlight the quality indicators that change the most. The following analyzes were performed for the liquid fraction of the studied beverages: TA-titratable acidity (g/100g, expressed as citric acid)(AOAC $942.15,2000)$; VA-acidity volatile $(\mathrm{g} / 100 \mathrm{~g}$, expressed as degree of acidity)(AOAC 925.34, 2000)(steam distillation apparatus Alcotest Raypa, Spain); TSS-soluble solid content ( ${ }^{\circ}$ Brix)(IS 13815:1993) (refractometer Krüss, Germany connected to a bath room ultrathermostated Brookfield, with the outer circulation); SDR-reducing directly sugar and total sugar (TS) content (\%) (AOAC, Method 925.35, 2000); nSDR anreducing directly sugar $(\mathrm{TS}-\mathrm{SDR}=\mathrm{nSDR})(\%)$; the kinematic viscosity $\left(\mathrm{m}^{2} \mathrm{~s}^{-1}\right)$ (Ubbelhode 3 branches viscometer no.1) (Will et al., 2008); relative density (AOAC-988.06) (DMA35, Spain); $\mathrm{pH}$ (pHmeter Orion 2-STAR, England).

\subsubsection{Statistical analysis of data}

The results are presented as the mean \pm standard deviation of 4 replicas. So, for the physico-chemical indicators for elderflower drinks, was been statistically analyzed. The calculation of the average value of the variables, the dispersion of the values and the correlation indices were done using the ANOVA statistical technique. Differences were considered significant at $\mathrm{P}<0,05$.

\section{Results and discussions}

\subsection{Production yield}

The elderflowers were picked up from May to June 2017 and they were used fresh. The harvest was made in a single geographical area (Teleajen Valley, Romania). Beverages made from water and inflorescences have been prepared that differ from one another by the applied technology. The yield in the extract ranges between 90 and $98(\mathrm{w} / \mathrm{w} \%)$ as shown in Table 1.

In other studies, the yield values in the aqueous sugar extract were reported to be between 69.6 and $82.7(\mathrm{w} / \mathrm{w} \%)$. These values were influenced by the genotype and the geographic area where the elder grew, and the technology used was similar to that in this study. In wild elder samples, the yield value was reported at 69.8-80.8 (w/w \%) (Kaack $e t$ al., 2006, 2008). Therefore, in the current study, the yield values in the juice are higher and are influenced by: the applied technology, the duration and the operational parameters of the fermentation process, the fermentation conditions, the fermentation degree, the recipe, the production losses.

\subsection{Comparative analysis of the values of the physical-chemical quality indicators}

The density of the analyzed sample, the relative density and the kinematic viscosity were investigated for the wild elder sweet beverages and listed in Table 1. These indicators were used to assess the quality of the fermented at $25^{\circ} \mathrm{C}$ or unfermented vegetable juices. The following were used for the preparation of the juices: water, sugar, fresh inflorescences, lemon with rind and high fermentation yeast, the Saccharomyces cerevisiae species. All these influence the value of the sample density. It varies between 1.0343 and $1.0590 \mathrm{~g} / \mathrm{cm}^{3}$ with the highest value of $1.0590 \mathrm{~g} / \mathrm{cm}^{3}$ for the newly obtained product, the elderflower compote (EC). According to the applied technology, there aren't any fermentation, manipulation or thermal treatment losses for this type of product 
preserved by abiosis. Density is the expression of the dry substance content in the unit of volume.

Consistent with the density, the fluid viscosity is their ability to resist flow. This is due to the mechanical interaction between the constituent particles. Thus, the more frequent these interactions, the higher the viscosity. In the studied samples, the kinematic viscosity value ranges between 1.30087 and 1.83902 $\mathrm{m}^{2} \mathrm{~s}^{-1}$, with the highest value for the newly obtained product, the compote.

Table 1. Technological and physical characteristics of beverages from fresh elderflowers

\begin{tabular}{|c|c|c|c|c|c|}
\hline $\begin{array}{c}\text { Code } \\
\text { sample }\end{array}$ & $\begin{array}{c}\text { Yield } \\
\text { of juice } \\
{[\mathbf{w} / \mathbf{w} \text { \%] }}\end{array}$ & $\begin{array}{c}\text { Sample } \\
\text { Density } \\
{\left[\mathbf{g} / \mathbf{c m}^{\mathbf{3}}\right]}\end{array}$ & $\begin{array}{c}\text { Water } \\
\text { Density } \\
\mathbf{a t} \mathbf{2 0} \mathbf{C}, \\
{\left[\mathbf{g} / \mathbf{c m}^{\mathbf{3}}\right]}\end{array}$ & $\begin{array}{c}\text { Relative } \\
\text { Density }\end{array}$ & $\begin{array}{c}\text { Kinematic } \\
\text { viscosity at } \\
\mathbf{2 0} \mathbf{C} \\
{\left[\mathbf{m}^{\mathbf{2}} \mathbf{s}^{-\mathbf{1}}\right]}\end{array}$ \\
\hline $\mathbf{E j F}^{\mathbf{1}}$ & $90 \pm 0.40$ & $1.0461 \pm 0.001$ & 0.9987 & $1.0475 \pm 0.0019$ & $1.1451 \pm 0.003$ \\
\hline $\mathbf{E j F P}^{\mathbf{2}}$ & $90 \pm 0.48$ & $1.0395 \pm 0.006$ & 0.9987 & $1.0408 \pm 0.0012$ & $1.3635 \pm 0.02$ \\
\hline $\mathbf{E j n F P}^{\mathbf{3}}$ & $92 \pm 0.75$ & $1.0343 \pm 0.001$ & 0.9987 & $1.0356 \pm 0.0013$ & $1.30087 \pm 0.004$ \\
\hline $\mathbf{E C}^{\mathbf{4}}$ & $98 \pm 1.31$ & $1.0590 \pm 0.006$ & 0.9987 & $1.06037 \pm 0.0030$ & $1.83902 \pm 0.005$ \\
\hline
\end{tabular}

The level of significance is $\mathrm{P}<0,05(\mathrm{n}=4)$. At the 0,05 level, the population mens are significantly different ${ }^{1}$ elderflower juice fermented with yeast; ${ }^{2}$ elderflower juice fermented with yeast preserved by pasteurization; ${ }^{3}$ elderflower juice unfermented with yeast preserved by pasteurization; ${ }^{4} \mathrm{c}$ elderflower compote with sugar.
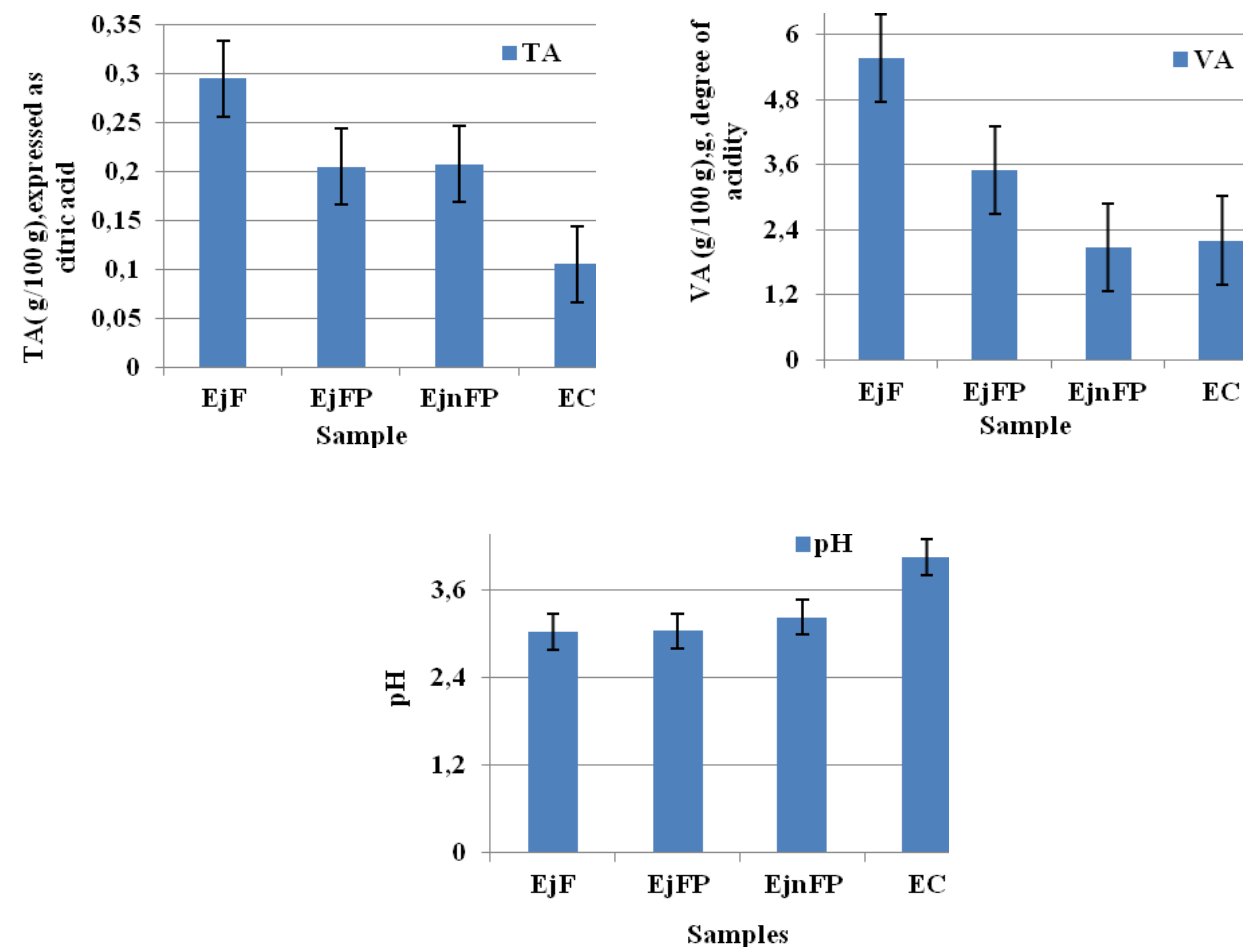

Figure 1. Total acidity (TA), volatile acidity (VA) and $\mathrm{pH}$ in the elderflowers juice and in the compote. The vertical bars correspond to the standard deviation $(n=4)$ 

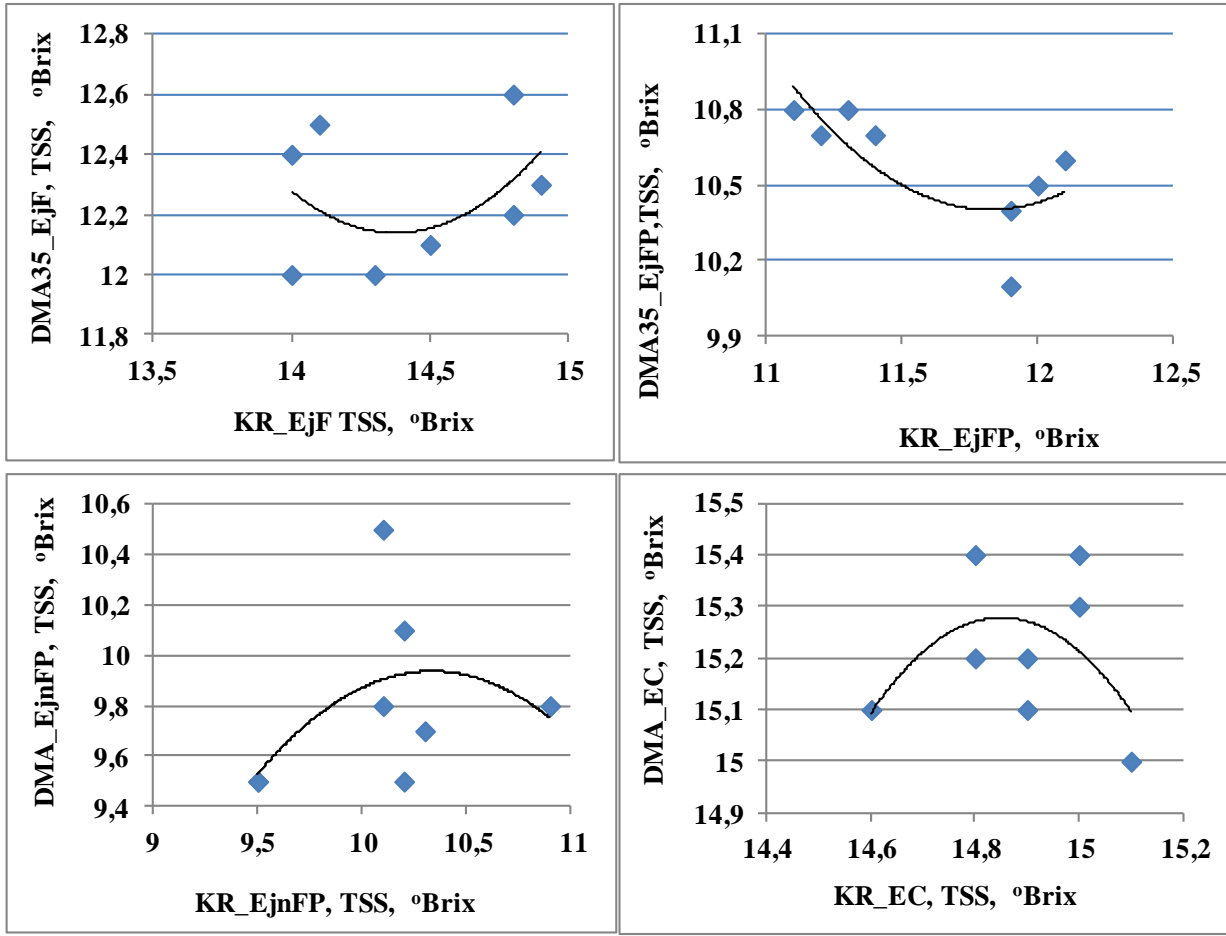

Figure 2. Soluble dry substance content (TSS) of the correlation values with the principle of the method used

Table 2. Variation of reducing sugar content determined chemically in elderflowes juice and total sugar/total acidity ratio

\begin{tabular}{|c|c|c|c|c|c|c|c|c|}
\hline \multirow{3}{*}{ Sample } & \multicolumn{8}{|c|}{ Variation in reducing sugars by the nature of the sample } \\
\hline & \multicolumn{4}{|c|}{${ }^{\mathrm{a}} \mathrm{SDR}(\%)$} & \multicolumn{4}{|c|}{ bnSDR(\%) } \\
\hline & Mean & $\begin{array}{l}\text { SE of } \\
\text { Mean }\end{array}$ & $\alpha^{*}$ & Sig. ${ }^{* *}$ & Mean & SE of mean & $a^{*}$ & Sig.** \\
\hline $\mathbf{E j F}$ & 10,525 & 0,18697 & \multirow{4}{*}{0,05} & \multirow{4}{*}{1} & 1,08 & 0,031 & \multirow{4}{*}{0,05} & \multirow{4}{*}{$0-1$} \\
\hline EjFP & 9,625 & 0,04349 & & & 2,9475 & 0,0228 & & \\
\hline EjnFP & 8,0425 & 0,01436 & & & 2,7925 & 0,1525 & & \\
\hline \multirow[t]{4}{*}{ EC } & 4,565 & 0,04992 & & & 10,242 & 0,0476 & & \\
\hline & \multicolumn{8}{|c|}{ Variation in total sugars and TS/TA ratio } \\
\hline & \multicolumn{3}{|c|}{ 'TS(\%) } & & \multicolumn{4}{|c|}{${ }^{\mathrm{d}} \mathbf{T S} / \mathbf{T A}$} \\
\hline & Mean & $\begin{array}{c}\text { SE } \\
\text { of Mean }\end{array}$ & $\alpha^{*}$ & Sig. ${ }^{\text {*** }}$ & Mean & $\begin{array}{c}\text { SE } \\
\text { of Mean }\end{array}$ & $\alpha^{*}$ & Sig.** \\
\hline EjF & 11,62 & 0,19074 & \multirow{4}{*}{0,05} & \multirow{4}{*}{1} & 47,74 & 5,1898 & \multirow{4}{*}{0,05} & \multirow{4}{*}{$0-1$} \\
\hline EjFP & 12,2725 & 0,16152 & & & 60,245 & 1,086 & & \\
\hline EjnFP & 10,2 & 0,09129 & & & 49,6225 & 0,847 & & \\
\hline EC & 14,96 & 0,02041 & & & 140,85 & 1,756 & & \\
\hline
\end{tabular}

* level of significance; $* *$ the mean of mean differences; ${ }^{\mathrm{a}-d i r e c t}$ reducing sugar; ${ }^{\mathrm{b}}$ sugar which is not directly reducing; ${ }^{\mathrm{c}}$ total sugar ; -total sugar ratio / acids giving total acidity 
One can observe the conformity between the values of the density, the relative density and the viscosity. That is, if one of them increases, the others increase as well because they are physical expressions of the chemical composition. The factors that influence these values are: the applied technology, the recipe used, the molecular structure of the constituent substances, the temperature at which the analysis was conducted.

The results of the modification of the chemical composition of the juices, expressed as TA (g/100g, expressed as citric acid), VA $(\mathrm{g} / 100 \mathrm{~g}$, expressed in degrees of acidity) and $\mathrm{pH}$ are shown in the graphs in Figure 1. These quality indicators are an expression of volatile components and those with acidic chemical groups.

There are 58 volatile components identified in the extract of flowering flowers (alcohol, aldehydes, ketones, terpenes, esters), acids such as citric acid, ascorbic acid (Kaack et al., 2006; Pabi et al., 2014; Petruţ et al., 2017), malic, tartaric, fumaric, shikimic in the total amount of $44.15 \mathrm{~g} / \mathrm{kg}$ DW with the highest proportion of malic acid (30.19 g/kg DW) (MikulicPetkovsek et al., 2016), as well as those resulting from the fermentations that take place in the extract. In this study, the TA values are between 0.11 and $0.3 \mathrm{~g} / 100 \mathrm{~g}$, expressed as citric acid, with the highest value for the $\mathrm{EjF}$ sample, which is fermented, and with the lowest value for the EC sample, the compote, which is only pasteurized. The same aspect applies to volatile acidity which ranges between 2 and $5.5 \mathrm{~g} / 100 \mathrm{~g}$, expressed in degrees of acidity. The $\mathrm{pH}$, another expression of the acidic components, has the same trend (inversely proportional, like value, to total acidity). It is noted that in the fermented samples the acidity is higher by about $43-64 \%$ compared to the unfermented ones. This aspect greatly influences the perception of the intensity of the sensory components: taste, aroma, flavor (Iancu, 2018). As influencing factors, from the variables of the procedures, it can be said that the production recipe, the fermentation degree, the thermal treatment and, according to other studies (Mikulic-Petkovsek et al., 2016) the genotype of the vegetal material bear a great influence.

The total soluble solid (TSS) content of the studied extracts and of the new product, the compote, are shown in Figure 2. It is a quality indicator which is present in all the analysis packages for the raw materials and the finished products from the vegetable canning industry (fruit and vegetable juices, sugar preserved vegetables and others) (Kaack et al, 2008; Marjan and Johari, 2010). That is why there are many items of equipment used for determination and which operate according to different physical principles. That is why the values of the TSS are not completely equal. Two devices (DMA 35 - portable electronic densimeter and Abbé refractometer) and two known physical principles were used for this study (the " $U$ " -tube principle, respectively the principle of total light refraction). The variation of values is done by polynomial regression equations, and the variation coefficients range between 0 and 1 .

At the sample EjF the variation is made by an equation of the form: $\mathrm{y}_{\mathrm{EjF}}=0.9775 \mathrm{x}^{2}-28.105 \mathrm{x}+214.6 ; \mathrm{R}_{\mathrm{EjF}}^{2}=0.1528$, with a correlation of $15 \%$. TSS values (refractometric method) are between (14-14.9) ${ }^{\mathrm{o}}$ Brix.

At the sample EjFP the variation is made by an equation of the form:

$\mathrm{y}_{\mathrm{EjFP}}=0.924 \mathrm{x}^{2}-21,871 \mathrm{x}+139.73 ; \quad \mathrm{R}_{\mathrm{EjFP}}^{2}=$ 0.5821 , with a correlation of $58 \%$. TSS values (refractometric method) are between (11.1-12) ${ }^{\mathrm{o}}$ Brix.

At the sample EjnFP the variation is made by an equation of the form: $\mathrm{y}_{\mathrm{EjnFP}}=0.585 \mathrm{x}^{2}+12.095 \mathrm{x}-52.573, \mathrm{R}^{2} \mathrm{EjnFP}=0.259$, with a correlation of $25 \%$. TSS values (refractometric method) are between (9.5-10.3) ${ }^{\mathrm{o}}$ Brix.

At the sample EC the variation is made by an equation of the form:

$$
\mathrm{y}_{\mathrm{EC}}=-2.916 \mathrm{x}^{2}+86,632 \mathrm{x}-628,02 \text {, }
$$
$\mathrm{R}^{2} \mathrm{EC}=0.278$, with a correlation of $27 \%$. TSS 
values (refractometric method) are between (14.6-15.1) ${ }^{\circ}$ Brix.

As can be seen from the results, the correlations between Ox:(KR) and Oy:(DMA35) are described by polynomial equations, the points being spread throughout the surface of the graph (Figure 2). The values of the correlation coefficient are very low, below 50\%, except for the EjFP sample. Therefore, it is recommended to refer to the standardized method, i.e. to the refractometric method.

The TSS content is given by the chemical composition of the extracts. Scientific literature reports that these Sambucus nigra concentrate elderflower extracts contain: sucrose

$27.35 \mathrm{~g} / \mathrm{kg} \mathrm{DW}$, glucose $19.71 \mathrm{~g} / \mathrm{kg} \mathrm{DW}$, fructose $24.28 \mathrm{~g} / \mathrm{kg}$ DW and a total sugar content of $71.34 \mathrm{~g} / \mathrm{Kg} \mathrm{DW}$ and an acid content of $44.15 \mathrm{~g} / \mathrm{kg}$ DW (Mikulic-Petkovsek et al., 2016). Along with polyphenols which were found in the amount of $40137 \mathrm{mg}$ GAE/ $/ \mathrm{kg}$ (Mikulic-Petkovsek et al., 2016) the substances mentioned above forms TSS.

In the samples of this study, apart from these substances, the added sucrose and the components migrated from lemon in the liquid phase and from the autolysis of the yeast cells contribute to the value of the TSS content. Thus a value of $14.6{ }^{\circ} \mathrm{Brix}$, for example, for the new product (the compote) (EC), is given by the added sugar, the sugars from the flowers, the acids in the elderflowers and the lemon slices. The TSS for the fresh or preserved vegetables and fruit juices ranges between $5^{\circ}$ Brix (for examples for the fresh juice of tomatoes) and $68{ }^{\circ}$ Brix in syrup. Thus the values for the elderflower beverage are consistent with those for the beverages typical of the canned industry

The content of reducing sugars in the vegetables juice is an important quality indicator. It contributes to the TSS value and the TS/TA ratio with great importance on the sensory characteristics of the juices (taste balance). For the studied samples, the average value for the sugar content is shown in Table 2. By using the method recommended by
ANOVA-One-Way (Fisher's LSD method), the confidence intervals created for all pairs differences between the level factors (very many values) are thus explained. The error rate was calculated and presented. According to the obtained results of the values for SDR and TS, at least one of the manufacturing means used to obtain the liquid fraction of the beverage varies significantly. For example, controlling the fermentation process is a key point in obtaining such different values.

At the Fischer test means comparison using equal 1 indicate that the difference of the mean is significant at the 0,05 level.

This method of statistical analysis was used because the variation of the results was great, which proves the influence of several factors such as: the variation of the

operational parameters of the technological schemes, the errors given by the analytical determinations. The only constant element was the variety of elderflowers and their condition (dried or fresh).

In conclusion, the highest direct reducing sugars (SDR) quantity is for the EjF sample (fresh fermented elderflower juice) with an average of $10.525 \mathrm{~g} / 100 \mathrm{~g}$ and the lowest of $4.565 \mathrm{~g} / 100 \mathrm{~g}$ in the EC sample (the elderflowers compote). These direct reducing sugars are given by the simple sugars: glucose and fructose that come from the elderflowers, from the sugars derived from the enzymatic hydrolysis of sucrose. If the fermentation of the mixture does not take place, the SDR is very law and is given only by the monosaccharides from the elderflowers.

In the fermented samples the TS content is much lower than the amount of sugar initially added to the sample (15\%, on average, according to the recipe) as compared to that of the newly created product, the EC.

The TS/TA ratio, for example, is a quality indicator in choosing the fruit used in juice making. For balanced taste characteristics, it is recommended that this ratio should be around 15. The TS/TA ratio for the elderflower sucrose-free concentrated aqueous extract is 
1.62 (Mikulic-Petkovsek et al., 2016). Therefore the rest is given by the addition of sugar in the samples of this study. The values obtained for this ratio are 104.85 for the new product, the elderflower compote, the highest value, and 47.74 for the fermented and freshly consumed $(\mathrm{EjF})$ variant. The higher this amount, the greater the quantity of sugars; meaning that the sweetness of the taste predominates. It is therefore noted that for the products presented here the recipe needs to be improved in terms of increasing the value of the acidic component of the taste. In a previous study it was shown that the EjF sample with the lowest value of the TS/TA ratio also obtained the highest score of the panelists in the sensory analysis (Iancu, 2018).

\section{Conclusions}

The correlated conclusions of the whole study on the fermented or not elderflower beverages are the following: the production yield is very high, with the highest value for the newly obtained product, the elderflowers compote, the values of the determined quality indicators are influenced by: the applied technology, the degree of fermentation (characterized by TSS and acidity), the duration of the fermentation, the nature of the used microorganisms (the use of the yeast species Saccharomyces cerevisiae), the method of preserving the juices, the shelf life, the chemical composition of the raw materials.

The closer to the neutral the $\mathrm{pH}$ value, the higher the TS/TA ratio. The value of the TS content in the studied samples, elderflower beverages, is close to the TSS value, demonstrating that the non-sugar in the liquid fraction is in a very small quantity, almost negligible, except for the EjF sample. In this sample, the difference in value, according to the data presented in the screenings, is due to the alcoholic fermentation, the lactic fermentation and other secondary fermentations and the lack of thermal treatment. The alcohol, the acids formed in fermentation may influence the TSS value, and therefore it is recommended to determine this value in the distilled liquid fraction rather than by direct reading.

\section{References}

A.O.A.C 17 th edn, (2000), Official method 942.15 Acidity (Titratable) of fruit products read with A.O.A.C official method 920.149 Preparation of test sample.

A.O.A.C 17 th edn, (2000), Official method 925.34 Acidity (Volatile) of fruit products, Steam Distillation method with A.O.A.C official method 964.08 acidity (Total Volatile) of wines http://www.aoacofficialmethod.org/index.p hp?main_page $=$ product_info\&cPath $=1 \& \mathrm{pr}$ oducts_id=2875

A.O.A.C 17 th edn, (2000), Official method 925.35 Sucrose in Fruits and Fruit Products

AOAC Official Method 988.06, Specific gravity of non pulp fruit juice beverages.

Day, I.(2010). "Cordial Waters", Historic Food. Retrieved.

FOASTAT,(2017). Food and Agriculture Organisation of the United Nation, www. fao.org/

Iancu, M.L.(2018). Comparative analysis of the aromatic, sensory profile of the elderflower (Sambucus nigra) compote, an innovative product, with beverages of "elder flower juice" type, Scientific Study \&Research Chemistry \& Chemical Engineering, Biotechnology, Food Industry, 19 (3), 257 $-267$.

I.S 13815:1993/ I.S.O 2173:1978 Fruit and Vegetable Products Determination of Soluble solid Content-Refractometer method

Kaack, K. (1997). Fruit Varieties Journal 51, 28-31

Kaack, K., Christensen, L.P., Hughes M., Eder, R. (2006). Relationship between sensory quality and volatile compounds of elderflower (Sambucus nigra L.) extracts. European Food Research and Technology, 223, 57-70.

Kaack, K., Xavier, C., Frette', Ć., Lars, P., Christensen Ć. A-K., Landbo, Ć. A., 
Meyer, S. (2008). Selection of elderberry (Sambucus nigra L.) genotypes best suited for the preparation of juice. European Food Research and Technology, 226, 843-855.

Marjan, J. and Johari, E, (2010). Survey on Rheological Properties of Fruit Jams, International Journal of Chemical Engineering and Applications, http://www.ijcea.org/list-7-1.html, 1(1).

Mikulic-Petkovsek, M., Ivancic, A., Schmitzer, A.,Veberic,V., Robert, Stampar R.F. (2016). Comparison of major taste compounds and antioxidative properties of fruits and flowers of different Sambucus species and interspecific hybrids, Food Chemistry, 200, 134-140

Mihalev, K., Dinkova, R., Shikov, V., Mollov, $\mathrm{P},(2018)$. Classification of fruit juices, Fruit juices Extraction, Composition, Quality and Analysis, Elssevier Academic Press, http://doi.org/101016/B978-0-12-8022306.00003-5

Morton, M. (2004). Cupboard Love: A Dictionary of Culinary Curiosities (2 ed.), Insomniac Press, p. 91, ISBN 978-1894663-66-3, retrieved 2011-03-13

Olejnik, A, Olkowicz, M., Kowalska, K., Rychlik, J, Dembczyński, R., Myszka, K., Juzwa, W., Białas, W., Moyer, M.P. (2016). Gastrointestinal digested Sambucus nigra L. fruit extract protects in vitro cultured human colon cells against oxidative stress. Food Chemistry, 197(Pt A),648-657.

Pabi, N., Innerhofer, G., Leitner, E., Siegmund B. (2014). The Flavor of Elderflower Species Differentiation via Flavor Compounds. Chapter 17:95-99

Petruţ, S.G., Muste, S., Mureșan, C., Păucean, A., Mureşan, E.A., Nagy, M. (2017). Chemical Profiles and Antioxidant Activity of Black Elder (Sambucus Nigra L.)-A Review, Bulletin UASVM Food Science and Technology, 74(1),

Vlachojannis, C., Zimmermann, B.F., Chrubasik-Hausmann, S. (2015). Quantification of anthocyanins in elderberry and chokeberry dietary supplements. Phytother Resources, 29(4), 561-565.

Walkowiak-Tomczak, K.D.(2017) Bioactive properties of elderflowers (Sambucus nigra L.). World Scientific News WSN 73(2) 115119.

Will, J.C., Hernández, I., Trujillo, S., (2008). Automated Measurement of Viscosity with Ubbelohde Viscometers, Camera Unit and Image Processing Software, Simposio de Metrología 2008 Santiago de Querétaro, México. 